\title{
CA724 predicts overall survival in locally advanced gastric cancer patients with neoadjuvant chemotherapy
}

Yilin Tong, Yan Zhao, Zexing Shan and Jianjun Zhang *i)

\begin{abstract}
Background: Serum tumor markers including AFU, AFP, CEA, CA199, CA125 and CA724, are of great importance in the diagnosis, prognostic prediction and recurrence monitoring of gastrointestinal malignancies. However, their significance in gastric cancer (GC) patients with neoadjuvant therapy (NCT) is still uncertain. The aim of this study was to evaluate the predictive value of these six tumor markers in locally advanced GC patients who underwent NCT and curative surgery.

Methods: In total, 290 locally advanced GC patients who underwent NCT and D2 radical gastrectomy were retrospectively analyzed. Data on their tumor markers before (pre-) and after (post-) NCT and pathological characteristics were extracted from the database of our hospital. The optimal cutoff values of the six tumor markers were calculated by the ROC curve and Youden index. Their predictive significance was analyzed and survival curves for overall survival (OS) were obtained by the Kaplan-Meier method. Associations between categorical variables were explored by the chi-square test or Fisher's exact test. Multivariate analyses were performed by the Cox regression model.
\end{abstract}

Results: Pre- and post-CA199, -CA125 and -CA724 could predict overall survival (all $P<0.05$ ), but only the change (diff-) of CA199 was related to prognosis $(P=0.05)$. In the multivariable analysis, pre- $(P=0.014)$ and post-CA724 $(P=0.036)$ remained significant, though diff-CA724 was not an independent prognostic factor $(P=0.581)$. In addition, pre- and post-CA199, -CA125 and -CA724 were associated with lymph node metastasis ( $\mathrm{N}-\mathrm{vs} \mathrm{N}+$ ) and pathological stage (I-II vs III) (all $P<0.05$ ). Moreover, post-CA724 was related to the vascular or lymphatic invasion $(P=0.019)$, while pre-CA724 was not $(P=0.082)$. However, AFU, AFP and CEA showed no association with survival $(P>0.05)$.

Conclusions: CA724 is an independent factor for prognosis and could be used to predict ypN and ypTNM stage in locally advanced GC patients undergoing NCT and curative resection.

Keywords: Gastric cancer, Tumor marker, Neoadjuvant therapy, CA199, CA125, CA724

\footnotetext{
* Correspondence: zhangjianjun@cancerhosp-In-cmu.com

Department of Gastric Surgery, Liaoning Cancer Hospital and Institute, Cancer Hospital of China Medical University, No 44 of Xiaoheyan Road,

Dadong District, Liaoning 110042 Shenyang, China
}

(c) The Author(s). 2020 Open Access This article is licensed under a Creative Commons Attribution 4.0 International License, which permits use, sharing, adaptation, distribution and reproduction in any medium or format, as long as you give appropriate credit to the original author(s) and the source, provide a link to the Creative Commons licence, and indicate if changes were made. The images or other third party material in this article are included in the article's Creative Commons licence, unless indicated otherwise in a credit line to the material. If material is not included in the article's Creative Commons licence and your intended use is not permitted by statutory regulation or exceeds the permitted use, you will need to obtain permission directly from the copyright holder. To view a copy of this licence, visit http://creativecommons.org/licenses/by/4.0/ The Creative Commons Public Domain Dedication waiver (http://creativecommons.org/publicdomain/zero/1.0/) applies to the data made available in this article, unless otherwise stated in a credit line to the data. 


\section{Background}

Gastric cancer (GC) is the fifth most frequently diagnosed cancer and the third leading cause of cancer death worldwide [1]. Excellent outcomes could be expected from surgery alone when gastric cancer is diagnosed at an early stage. However, in locally advanced GC patients, surgery does not always lead to a satisfactory outcome, even with postoperative therapy [2]. Neoadjuvant chemotherapy (NCT) improves the R0 resection rate and prognosis when compared with surgery alone or surgery with postoperative therapy [3], but the outcomes are vary due to the differences in many factors such as tumor differentiation and Lauren classification. More indicators to assess survival are urgently needed.

Serum tumor markers play important roles in the diagnosis, prognostic prediction and recurrence monitoring of gastrointestinal malignancies. As studies have suggested, AFU was considered to be related to liver metastasis in colorectal cancer [4]; AFP was associated with prognosis in gastric cancer patients undergoing surgery alone [5]; preoperative CEA could predict the prognosis of GC patients with no lymph node metastasis [6]; CA199 was an independent prognostic factor in gastroesophageal junction (GEJ) cancer patients who experienced surgery alone [7]; the CA125 level was related to the degree of peritoneal dissemination and the existence of malignant ascites in GC patients with peritoneal metastasis [8]; and CA724 was correlated with pTNM stage in gastric carcinoma patients [9]. However, for GC patients who underwent NCT, the evidence of these markers is still insufficient.

In this article, we investigated the prognostic significance of the six serum tumor markers before (pre-) and after (post-) NCT, the predictive value of changes (diff-) of tumor markers due to treatment, the innerrelationships among those markers and the connections between markers and other pathological factors in locally advanced GC patients.

\section{Methods}

Between June 2010 and July 2016, patients with locally advanced gastric adenocarcinoma (including gastroesophageal junction carcinoma) who underwent preoperative chemotherapy with or without postoperative treatment were identified from the database of our hospital. The inclusion criteria were as follows: (1) histopathological evidence of gastric adenocarcinoma; (2) locally advanced tumor (8th edition AJCC clinical staging II-III, T2N1M0-T4N3M0); (3) underwent NCT with or without postoperative treatment; and (4) underwent curative gastrectomy with D2 lymph node dissection. Patients who underwent preoperative radiotherapy, or suffered from other malignant tumors were excluded.

The levels of pre- and post-NCT serum tumor markers including AFU, AFP, CEA, CA199, CA125 and CA724, and other clinicopathological characteristics of all patients were extracted from our database.

The optimal cutoff values of all serum tumor markers and other continuous variables were calculated by ROC curves and the Youden index. The relationships of classified variables were computed by the chi-square test or Fisher's exact test, and intensities of association were evaluated by the coefficient of contingency ( $C$ value). Survival curves for overall survival (OS) were obtained using the Kaplan-Meier method, and the log-rank test was used to compare survival differences. Cox regression analysis was used to assess the hazard ratios of all factors for OS, and the factors with a $P$ value $\leq 0.05$ or with great importance in clinical diagnosis were included in the multivariable analysis. OS was calculated as the time from the initial treatment to death by any cause or the last follow-up. The data were analyzed with SPSS 25.0 software.

\section{Results}

\section{Patient characteristics}

From a total of 3196 patients, 290 patients met the inclusion criteria. Their clinicopathological features are shown in Table 1. There were 215 males (74.1\%) and 75 females $(25.9 \%)$, with an age range of $25-77$ years (median 59 years). Regarding the tumor location, a majority of tumors were located in the lower third part of the stomach $(59.3 \%)$, while $8(2.8 \%)$ were located in the GEJ, and $24(8.3 \%)$ were in the diffuse group. Most patients underwent preoperative therapy with SOX (73.8\%), and the median number of NCT cycle was 2 (range from 2 to 4). The median operation interval, the time from the end of neoadjuvant treatment to the surgery, was 4 weeks (range from 1 to 9). Thirty-one (10.7\%) patients did not receive postoperative treatment. The median follow-up time of all patients was 41 months (range from 3 to 91 months).

Pathologically, the average number of removed lymph nodes was 27, and $100(34.5 \%)$ patients had no lymph node metastasis. Nearly half of the tumors (49.3\%) were the intestinal type, and only one-fourth (25.2\%) were well differentiated. Patients with vascular or lymphatic invasion (VOLI) accounted for $24.8 \%$, while those with nerve invasion (NI) accounted for $23.4 \%$.

\section{Prognostic significance of serum tumor markers}

Because of the nature of retrospective studies, not all patients had data on the six serum tumor markers. The 
Table 1 Clinicopathological characteristics

\begin{tabular}{|c|c|c|c|c|c|}
\hline Characteristics & No. of patients & Percent & Characteristics & No. of patients & Percent \\
\hline Gender & & & Poorly cohesive carcinoma & 104 & 35.9 \\
\hline Male & 215 & 74.1 & Lauren classification & & \\
\hline Female & 75 & 25.9 & Intestinal & 143 & 49.3 \\
\hline Age & & & Diffuse or Mixed & 147 & 50.7 \\
\hline$<65$ & 221 & 76.2 & Grade of differentiation & & \\
\hline$\geq 65$ & 69 & 23.8 & Well & 70 & 25.2 \\
\hline Blood type & & & Moderate or Poor & 220 & 74.8 \\
\hline A & 101 & 34.8 & Vascular or lymphatic invasion & & \\
\hline B & 73 & 25.2 & No & 218 & 75.2 \\
\hline$A B$ & 28 & 9.7 & Yes & 72 & 24.8 \\
\hline $\mathrm{O}$ & 88 & 30.3 & Nervous invasion & & \\
\hline Smoking & & & No & 222 & 76.6 \\
\hline No & 128 & 44.1 & Yes & 68 & 23.4 \\
\hline Yes & 162 & 55.9 & Neoadjuvant therapy & & \\
\hline Drinking & & & SOX & 214 & 73.8 \\
\hline No & 194 & 66.9 & XELOX & 21 & 7.2 \\
\hline Yes & 96 & 33.1 & FOLFOX & 55 & 19.0 \\
\hline Family history & & & Adjuvant treatment & & \\
\hline No & 230 & 79.3 & No & 31 & 10.7 \\
\hline Yes & 60 & 20.7 & Yes & 259 & 89.3 \\
\hline
\end{tabular}

Table 1 Clinicopathological characteristics (Continued)

$\begin{array}{ll}\text { Upper third } & 32 \\ \text { Middle third } & 54 \\ \text { Lower third } & 172 \\ \text { Diffuse } & 24\end{array}$

Tumor size $(\mathrm{cm})$

$\begin{array}{ll}<5 & 115 \\ \geq 5 & 175\end{array}$

ypT

$0 \quad 9$

$1-2 \quad 57$

3-4 224

ypN

0

$1 \quad 49$

279

3

ypTNM

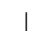

॥

III

Histological type

Adenocarcinoma

\section{8}

32

54

57

24

number of patients whose markers were available before and after NCT are shown in Additional file 1. The levels of pre- serum tumor markers were measured within 4 weeks before the beginning of NCT, and the post- serum levels were measured within 2 weeks before gastrectomy.

The univariate analysis outcomes of every marker are listed in Table 2, and the survival curves are shown in Figs. 1, 2, and 3. These results indicated that for CA199, CA125 and CA724, all positive groups had a worse prognosis (all $P<0.05$ ). For AFU, AFP and CEA, no significant difference was found (all $P>0.05)$.

Pre-, post-, and diff-CEA, -CA199, -CA125 and -CA724 were included in the multivariate analysis (Table 3). In the pre- and post- groups, CA724 was an independent prognostic factor, while other markers did not. However, in diff- group, CA724 lost its predicting value $(P=0.581)$, though $C A 125$ was an independent prognostic factor $(P=0.034)$.

\section{Correlation within serum tumor markers}

Because the significance of the tumor markers except for CA724 was lost in multivariate analysis, we analyzed the interconnections between these markers. Their coefficients of contingency are shown in Table 4. In the pre- group, the positive rates of CA199 $(P=$ $0.005)$ and CA125 $(P=0.015)$ were significantly higher 
Table 2 Univariate analysis of tumor markers

\begin{tabular}{|c|c|c|}
\hline Tumor marker & Hazard ratio $(95 \% \mathrm{Cl})$ & $P$ value \\
\hline pre-AFU > 45.1 & $1.607(0.504,5.126)$ & 0.423 \\
\hline pre-AFP $>2.6$ & $1.294(0.810,2.066)$ & 0.280 \\
\hline pre-CEA > 1.6 & $1.193(0.841,1.893)$ & 0.322 \\
\hline pre-CA199> 24.9 & $1.729(1.187,2.519)$ & 0.004 \\
\hline pre-CA125> 16 & $2.337(1.515,3.606)$ & 0.000 \\
\hline pre-CA724 > 4.6 & $2.033(1.391,2.972)$ & 0.000 \\
\hline post-AFU $>40.9$ & $0.995(0.517,1.915)$ & 0.988 \\
\hline post-AFP $>4.6$ & $1.697(0.958,3.005)$ & 0.070 \\
\hline post-CEA > 3.3 & $1.220(0.813,1.831)$ & 0.337 \\
\hline post-CA199>62.6 & $2.447(1.515,3.954)$ & 0.000 \\
\hline post-CA125> 11.2 & $2.187(1.352,3.536)$ & 0.001 \\
\hline post-CA724> 5.9 & $2.246(1.460,3.455)$ & 0.000 \\
\hline diff-AFU $>0$ & $0.742(0.290,1.899)$ & 0.533 \\
\hline diff-AFP $>0$ & $1.017(0.718,1.439)$ & 0.924 \\
\hline diff-CEA $>0$ & $0.992(0.814,1.120)$ & 0.940 \\
\hline diff-CA199>0 & $1.217(1.000,1.481)$ & 0.050 \\
\hline diff-CA125 >0 & $1.190(0.932,1.520)$ & 0.163 \\
\hline diff-CA724 >0 & $1.186(0.946,1.486)$ & 0.139 \\
\hline
\end{tabular}

Units: AFU(U/L); AFP (ng/ml); CEA (ng/ml); CA199(U/ml); CA125(U/ml); CA724(U/ml)

when CEA was positive, and the positive rates of CA125 $(P=0.001)$ and CA724 $(P=0.002)$ were significantly higher when CA199 was positive. However, for the post- indicators, only the relation between CEA and CA125 was still remarkable $(P=0.014)$.
Associations were also found in the diff-group, although the correlations among all tumor markers were not very strong (all $\mathrm{C}$ values $<0.3$ ).

\section{Relationship between the serum tumor markers and pathological factors}

The correlations between the markers and pathological factors were analyzed (Table 5). The lymph node metastasis rates were significantly higher in the positive groups of pre- and post-CA199, -CA125 and -CA724. In the diff- category, no correlation was found. The increase of pre- and post-CA199 and CA125 could predict a worse ypTNM stage (all $P<$ $0.05)$. Although pre-CA724 owned a similar function $(P=0.007)$, the post- serum level lost its ability to predict the pathological stage $(P=0.098)$. In terms of VOLI, only post-CA724 was related to the invasion rate $(P=0.019)$. In addition, there was no correlation between the markers and NI.

\section{Discussion}

Serum tumor markers are widely applied in diagnosis, therapeutic effect assessment and disease recurrence monitoring [9], and a series of studies have explored the diagnostic and prognostic value of various serum tumor markers in gastric cancer [10]. However, most of these studies were based on patients who had undergone surgery with or without adjuvant therapy, and only a few focused on patients with NCT in gastric cancer $[11,12]$.
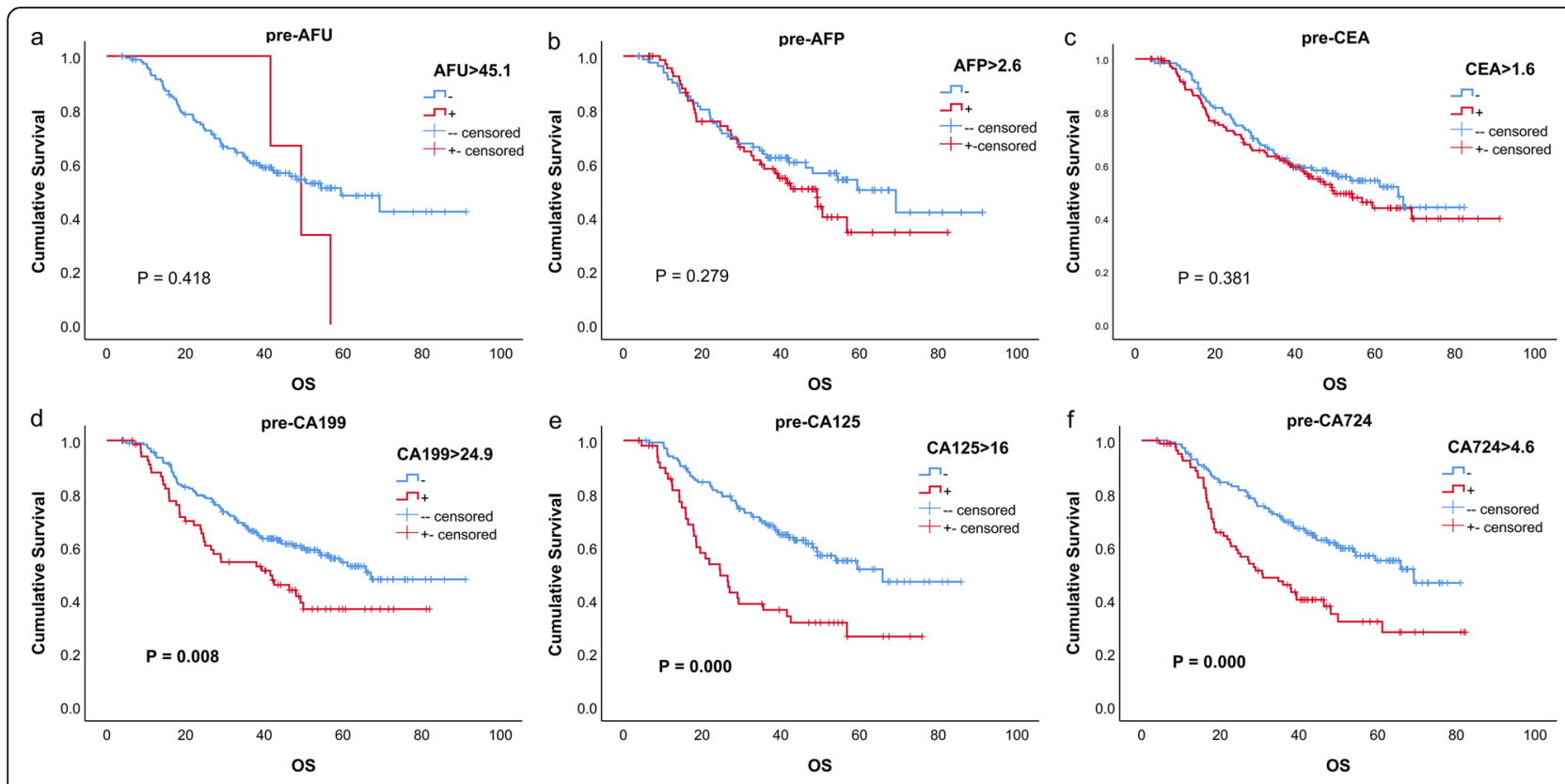

Fig. 1 Kaplan-Meier curves of six tumor markers before neoadjuvant therapy 

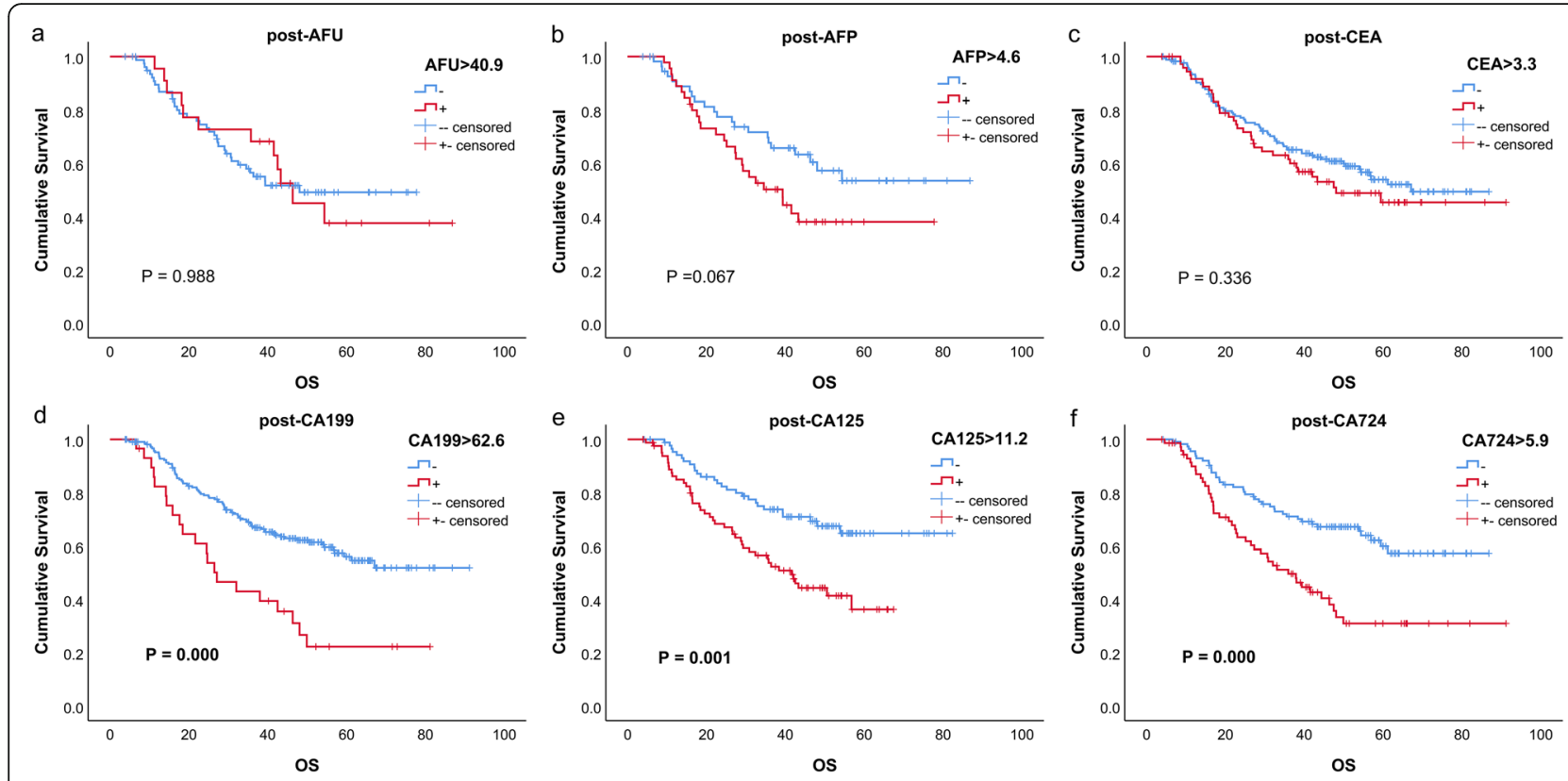

Fig. 2 Kaplan-Meier curves of six tumor markers after neoadjuvant therapy

Other studies have shown that, CA125 was associated with the R0 resection rate [13], recurrence, peritoneal dissemination [14] and OS in unresectable advanced or recurrent GC patients [15]; CA199 was related to $\mathrm{pN}[7,16-18]$ and $\mathrm{pTNM}$ stage [17]; and CA724 was related to the pathological stage and had a good diagnostic value for gastric cancer [19].
However, none of the patients in those studies underwent NCT.

In our study, the levels of CA199, CA125 and CA724 before and after NCT could predict prognosis, and the changes of CA199 and CA125 were related to the outcome. Similar results had been presented by many studies based on GC patients without NCT $[8$,

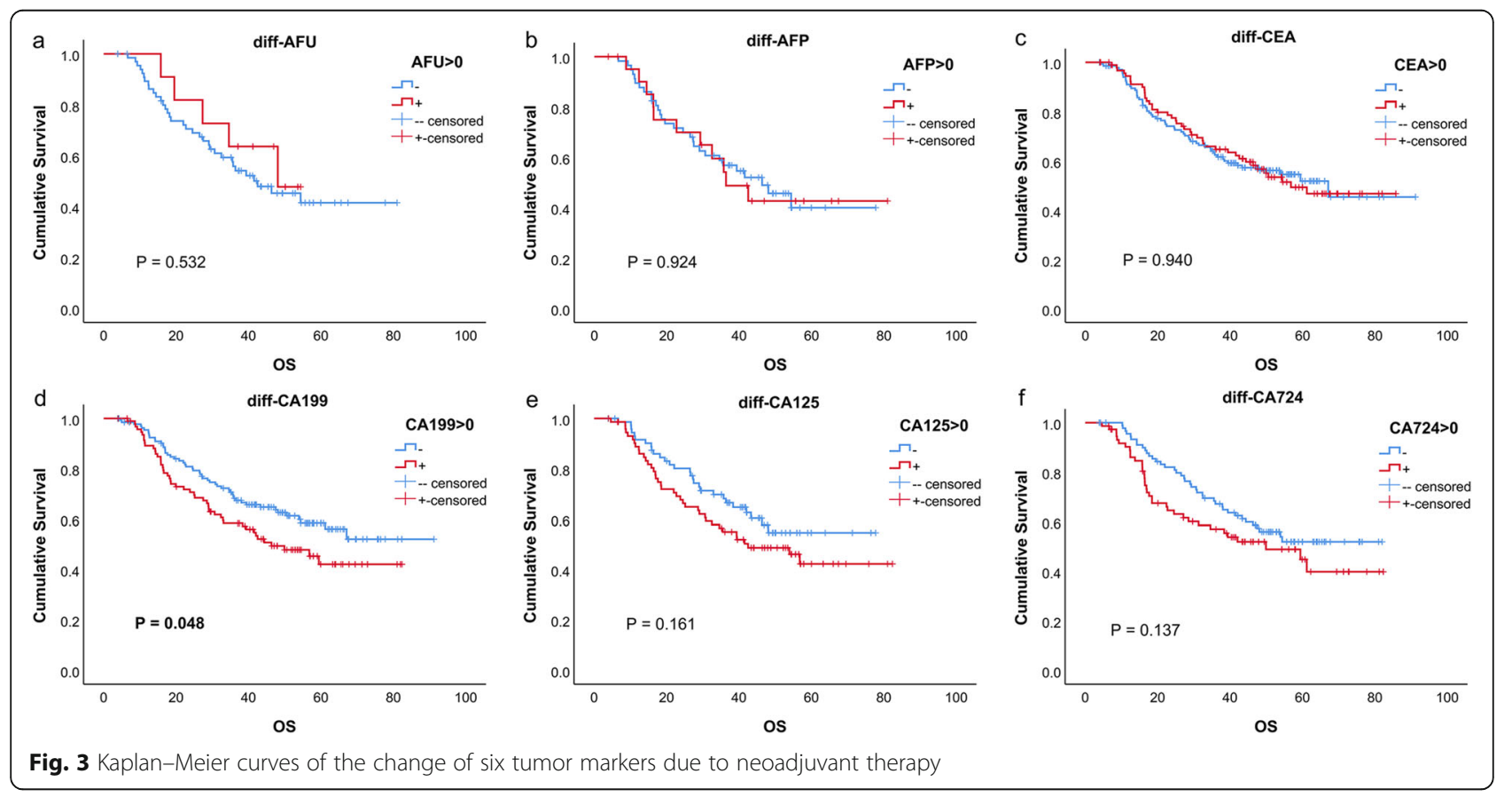


Table 3 Multivariate analysis of all characteristics on overall survival

\begin{tabular}{|c|c|c|c|c|c|c|}
\hline Variable & pre-HR $(95 \% \mathrm{Cl})$ & $P$ value & post-HR $(95 \% \mathrm{Cl})$ & $P$ value & diff-HR $(95 \% \mathrm{Cl})$ & $P$ value \\
\hline Age & $1.049(0.565,1.948)$ & 0.879 & $0.569(0.254,1.272)$ & 0.169 & $0.556(0.242,1.277)$ & 0.166 \\
\hline Tumor Location & & $0.160^{*}$ & & $0.020^{*}$ & & $0.318^{*}$ \\
\hline Upper third & 1 & & 1 & & 1 & \\
\hline GEJ & $0.298(0.048,1.849)$ & 0.194 & $0.470(0.060,3.698)$ & 0.473 & $0.314(0.025,3.883)$ & 0.367 \\
\hline Middle third & $0.512(0.186,1.406)$ & 0.194 & $0.108(0.020,0.586)$ & 0.010 & $0.192(0.031,1.205)$ & 0.078 \\
\hline Lower third & $0.532(0.222,1.278)$ & 0.158 & $0.265(0.083,0.844)$ & 0.025 & $0.542(0.163,1.801)$ & 0.318 \\
\hline Diffuse & $1.170(0.420,3.259)$ & 0.763 & $0.872(0.261,2.912)$ & 0.824 & $0.876(0.216,3.556)$ & 0.853 \\
\hline Tumor Depth $(\mathrm{cm})$ & $1.493(0.738,3.023)$ & 0.265 & $1.695(0.615,4.669)$ & 0.308 & $1.655(0.610,4.488)$ & 0.322 \\
\hline ypT & & $0.425^{*}$ & & $0.051^{*}$ & & $0.109^{*}$ \\
\hline 0 & 1 & & 1 & & 1 & \\
\hline $1-2$ & $0.212(0.016,2.860)$ & 0.243 & $0.103(0.005,2.333)$ & 0.153 & $0.129(0.006,2.933)$ & 0.199 \\
\hline $3-4$ & $0.414(0.022,7.627)$ & 0.553 & $1.207(0.020,71.782)$ & 0.928 & $1.018(0.019,55.965)$ & 0.993 \\
\hline ypN & & $0.036^{*}$ & & $0.003^{*}$ & & $0.004^{*}$ \\
\hline 0 & 1 & & 1 & & 1 & \\
\hline 1 & $6.372(1.280,31.734)$ & 0.024 & $45.419(6.213,332.002)$ & 0.000 & $26.013(3.647,185.553)$ & 0.001 \\
\hline 2 & $7.865(1.399,44.214)$ & 0.019 & $36.926(4.488,303.797)$ & 0.001 & $21.381(2.539,180.016)$ & 0.005 \\
\hline 3 & $13.512(2.217,82.368)$ & 0.005 & $49.034(5.063,474.881)$ & 0.001 & $52.701(5.358,518.388)$ & 0.001 \\
\hline ypTNM & & $0.759^{*}$ & & $0.192^{*}$ & & $0.256^{*}$ \\
\hline I & 1 & & 1 & & 1 & \\
\hline$\|$ & $1.449(0.209,10.075)$ & 0.708 & $0.582(0.031,10.892)$ & 0.718 & $0.571(0.028,11.584)$ & 0.716 \\
\hline III & $0.927(0.059,14.55)$ & 0.957 & $0.103(0.002,5.181)$ & 0.256 & $0.114(0.002,5.424)$ & 0.271 \\
\hline Histological type & $0.583(0.309,1.097)$ & 0.094 & $1.234(0.562,2.710)$ & 0.600 & $1.168(0.515,2.648)$ & 0.710 \\
\hline Lauren Classification & $1.774(0.972,3.238)$ & 0.062 & $0.919(0.426,1.982)$ & 0.830 & $1.022(0.422,2.476)$ & 0.961 \\
\hline Grade of differentiation & $2.592(1.074,6.257)$ & 0.034 & $3.495(0.980,12.457)$ & 0.054 & $4.807(1.345,17.176)$ & 0.016 \\
\hline VOLI & $1.623(0.925,2.849)$ & 0.091 & $4.532(2.045,10.043)$ & 0.000 & $2.529(1.005,6.364)$ & 0.049 \\
\hline $\mathrm{NI}$ & $0.946(0.543,1.646)$ & 0.843 & $0.957(0.501,1.829)$ & 0.894 & $1.120(0.544,2.305)$ & 0.758 \\
\hline Adjuvant therapy & $3.421(1.488,7.866)$ & 0.004 & $5.853(1.919,17.852)$ & 0.002 & $7.236(2.419,21.647)$ & 0.000 \\
\hline CEA & $1.265(0.712,2.247)$ & 0.423 & $1.105(0.511,2.390)$ & 0.800 & $0.903(0.399,2.044)$ & 0.807 \\
\hline CA199 & $0.984(0.530,1.829)$ & 0.960 & $1.570(0.606,4.066)$ & 0.353 & $1.032(0.483,2.206)$ & 0.936 \\
\hline CA125 & $1.503(0.821,2.754)$ & 0.187 & $1.492(0.774,2.878)$ & 0.232 & $2.353(1.068,5.184)$ & 0.034 \\
\hline CA724 & $2.177(1.169,4.056)$ & 0.014 & $2.349(1.057,5.220)$ & 0.036 & $1.238(0.581,2.638)$ & 0.581 \\
\hline
\end{tabular}

VOLI Vascular or lymphatic invasion, $N I$ Nervous invasion, GEJ Gastroesophageal junction; *P values from joint tests

13, 19, 20]. Nevertheless, we found that only CA724 was an independent prognostic factor in the multivariable analysis before and after NCT. It is noteworthy that this independent significance was lost in the diffgroup, which was different from the findings of some studies. Zou et al. [11] claimed that the change in CA724 could reflect the therapeutic effect of NCT. Another paper suggested that a decrease in CA724 could lead to a better prognosis [12]. The difference in findings might be because more clinicopathological factors were included in the multivariable analysis in our study. Despite this, CA724 was still an independent predictive factor for GC patients who had undergone NCT.
Although CA724 had a high diagnostic value in GC, its sensitivity was only approximately $45.0 \%$ [19]. Moreover, in China, CA724 has been suggested to be associated with Helicobacter pylori infection [21] and even geographical environmental factors, such as temperature [22]. These findings imply that there might be a bias to evaluate the condition of patients merely depending on CA724. Much work has been done to address this problem. For example, TKI, an enzyme involved in the regulation of the mammalian cell cycle, was another choice of marker in gastric cancer [19]. Moreover, the combination of CA724, CA199, CA125 and CEA could also improve the diagnostic capability $[9,12,19,23]$.. 
Table 4 Coefficient of contingency ( $C$ value) among tumor markers

\begin{tabular}{|c|c|c|c|c|c|}
\hline Markers & & & & $C$ value & $P$ value \\
\hline pre-CEA & & - & + & & \\
\hline \multirow[t]{2}{*}{ pre-CA199 } & - & 104 & 96 & 0.169 & 0.005 \\
\hline & + & 22 & 46 & & \\
\hline \multirow[t]{2}{*}{ pre-CA125 } & - & 71 & 62 & 0.177 & 0.015 \\
\hline & + & 17 & 34 & & \\
\hline pre-CA199 & & - & + & & \\
\hline \multirow[t]{2}{*}{ pre-CA125 } & - & 109 & 27 & 0.230 & 0.001 \\
\hline & + & 29 & 22 & & \\
\hline \multirow[t]{2}{*}{ pre-CA724 } & - & 115 & 25 & 0.205 & 0.002 \\
\hline & + & 52 & 30 & & \\
\hline post-CEA & & - & + & & \\
\hline \multirow[t]{2}{*}{ post-CA199 } & - & 152 & 57 & 0.125 & 0.052 \\
\hline & + & 16 & 13 & & \\
\hline \multirow[t]{2}{*}{ post-CA125 } & - & 67 & 20 & 0.185 & 0.014 \\
\hline & + & 50 & 34 & & \\
\hline \multirow[t]{2}{*}{ post-CA724 } & - & 85 & 27 & 0.133 & 0.069 \\
\hline & + & 45 & 26 & & \\
\hline post-CA199 & & - & + & & \\
\hline \multirow[t]{2}{*}{ post-CA125 } & - & 82 & 5 & 0.130 & 0.089 \\
\hline & + & 71 & 11 & & \\
\hline diff-CEA & & - & + & & \\
\hline \multirow[t]{2}{*}{ diff-CA199 } & - & 45 & 47 & 0.150 & 0.024 \\
\hline & + & 44 & 86 & & \\
\hline \multirow[t]{2}{*}{ diff-CA125 } & - & 32 & 41 & 0.136 & 0.098 \\
\hline & + & 22 & 50 & & \\
\hline diff-CA199 & & - & + & & \\
\hline \multirow[t]{2}{*}{ diff-CA125 } & - & 40 & 32 & 0.165 & 0.045 \\
\hline & + & 28 & 44 & & \\
\hline \multirow[t]{2}{*}{ diff-CA724 } & - & 36 & 36 & 0.203 & 0.008 \\
\hline & + & 27 & 64 & & \\
\hline
\end{tabular}

Only results with $P \leq 0.1$ were listed

Regarding pathological factors, we found that CA199, CA125 and CA724 before and after NCT were all correlated with lymph node metastasis and ypTNM stage. In previous studies of GC patients who underwent curative gastrectomy, preoperative CA199 could predict lymph node metastasis [17, 18] and pTNM stage [17]. CA724 was associated with nodal involvement [9] and pathological stage in advanced gastric cancer patients [19]. To supplement those findings, we confirmed them in patients with preoperative therapy. In addition, we found that CA125 was also related to ypN and ypTNM stage.
In our study, the VOLI rate was significantly higher in the positive post-CA724 group, while in pre-CA724 group, the difference was not significant. However, Sun et al. [12] suggested that pre-CA724 was related to vascular invasion. This finding might suggest that CA724 could be used to assess lymphatic or vascular invasion, but more evidence is needed.

It was unexpected that CEA was not related to prognosis in our study. The reasons might include that a different cutoff value was used in our study, and NCT might influence the predictive value of the tumor marker. Although a team from Japan supported a similar result [7], a large number of studies suggested the opposite result $[10,16,18,24]$. Nevertheless, in our study, CEA was related to CA199 and CA125, which was in line with other studies [7, 19]. It is noteworthy that these connections weakened after NCT, which might mean that preoperative treatment could blur these relationships.

The limitations still exist in this study. First, due to the nature of retrospective research, some patients did not have all values of the markers, which hindered the exploration of the combination of markers. Second, the sample size was not large enough. The sample numbers of AFU and AFP in every group were so small that they were not included in the further analysis. This limitation might also contribute to the reason why some $P$ values were more than 0.05 but smaller than 0.1. Third, we used the optimal cutoff values derived from the Youden index, which disturbed the comparison with other studies.

Despite these limitations, our study still has some merits. Our sample size is relatively small, but we focused on a specific group of patients. The cutoff values of tumor markers used in our study were calculated by statistical methods, because there is lack of strong evidence on the optimal cutoff values, which might vary according to the therapy, tumor location, and even geographical features. We not only illuminated the prognostic significance of these tumor markers, but also confirmed their abilities to predict lymph node metastasis and pathological stage. These results are useful for assessing the condition of patients and making further clinical decisions.

\section{Conclusions}

CA724 levels before and after neoadjuvant chemotherapy were both independent prognostic factors in GC patients undergoing NCT and curative surgery. Pre- and post-CA724 could also be used to predict lymph node metastasis and pathological stage. However, the change of CA724 due to preoperative treatment was not related to the prognosis in the multivariate analysis. 
Table 5 Relationship between serum tumor markers and pathological factors

\begin{tabular}{|c|c|c|c|c|c|c|c|c|c|c|}
\hline & & \multicolumn{2}{|c|}{ N stage } & \multirow[t]{2}{*}{$P$ value } & \multicolumn{2}{|c|}{ урTNM } & \multirow[t]{2}{*}{$P$ value } & \multicolumn{2}{|c|}{ VOLI } & \multirow[t]{2}{*}{$P$ value } \\
\hline & & $\mathrm{N}-$ & $\mathrm{N}+$ & & $|-| \mid$ & III & & + & - & \\
\hline \multirow[t]{2}{*}{ pre-CA199 } & - & 80 & 125 & 0.009 & 93 & 112 & 0.050 & 156 & 49 & 0.400 \\
\hline & + & 15 & 54 & & 22 & 47 & & 49 & 20 & \\
\hline \multirow[t]{2}{*}{ pre-CA125 } & - & 62 & 74 & 0.000 & 69 & 67 & 0.001 & 102 & 34 & 0.116 \\
\hline & + & 6 & 46 & & 12 & 40 & & 33 & 19 & \\
\hline \multirow[t]{2}{*}{ pre-CA724 } & - & 49 & 92 & 0.039 & 63 & 78 & 0.007 & 110 & 31 & 0.082 \\
\hline & + & 18 & 65 & & 22 & 61 & & 56 & 27 & \\
\hline \multirow[t]{2}{*}{ post-CA199 } & - & 81 & 133 & 0.003 & 100 & 114 & 0.003 & 159 & 55 & 0.559 \\
\hline & + & 3 & 26 & & 5 & 24 & & 23 & 6 & \\
\hline \multirow[t]{2}{*}{ post-CA125 } & - & 44 & 44 & 0.001 & 49 & 39 & 0.014 & 65 & 23 & 0.854 \\
\hline & + & 22 & 62 & & 31 & 53 & & 61 & 23 & \\
\hline \multirow[t]{2}{*}{ post-CA724 } & - & 45 & 69 & 0.022 & 53 & 61 & 0.098 & 91 & 23 & 0.019 \\
\hline & + & 17 & 56 & & 25 & 48 & & 47 & 26 & \\
\hline \multirow[t]{2}{*}{ diff-CA199 } & - & 34 & 62 & 0.833 & 41 & 55 & 0.969 & 70 & 26 & 0.650 \\
\hline & + & 46 & 89 & & 58 & 77 & & 102 & 33 & \\
\hline \multirow[t]{2}{*}{ diff-CA125 } & - & 23 & 51 & 0.152 & 32 & 42 & 0.567 & 52 & 22 & 0.754 \\
\hline & + & 31 & 42 & & 35 & 38 & & 53 & 20 & \\
\hline \multirow[t]{2}{*}{ diff-CA724 } & - & 24 & 50 & 0.669 & 26 & 48 & 0.275 & 50 & 24 & 0.223 \\
\hline & + & 27 & 65 & & 40 & 52 & & 70 & 22 & \\
\hline
\end{tabular}

VOLI Vascular or lymphatic invasion

\section{Supplementary Information}

Supplementary information accompanies this paper at https://doi.org/10. 1186/s12885-020-07666-8.

Additional file 1. Number of patients with different tumor markers.

\section{Abbreviations}

AFU: Alpha-I-fucosidase; AFP: Alpha-fetoprotein; CEA: Carcinoembryonic antigen; CA199: Carbohydrate antigen 19-9; CA125: Cancer antigen 125; CA724: Carbohydrate antigen 72-4; ypTNM: post-neoadjuvant therapy TNM stage; pTNM: pathological TNM stage; GC: Gastric cancer; NCT: Neoadjuvant therapy; OS: Overall survival; AJCC: American Joint Committee on Cancer; VOLI: Vascular or lymphatic invasion; NI: Nervous invasion

\section{Acknowledgments}

Not applicable.

\section{Authors' contributions}

$Y T$ performed the majority of experiments and analyzed the data and drafted the manuscript; YZ reviewed and revised the manuscript; ZS assisted in collected and analyzed the data; JZ supervised the study and provided critical revision of the manuscript. All authors have read and approved the manuscript.

\section{Funding}

Not applicable.

\section{Availability of data and materials}

The datasets used and/or analyzed during the current study are available from the corresponding author on reasonable request.
Ethics approval and consent to participate

The study was reviewed and approved by the Faculty of Science Ethics Committee at Liaoning Cancer Hospital and Institute (Cancer Hospital of China Medical University). This is a retrospective study and all patients have signed the informed consent prior to treatment.

\section{Consent for publication}

Not applicable.

\section{Competing interests}

The authors declare that they have no competing interests.

Received: 11 November 2019 Accepted: 19 November 2020

Published online: 05 January 2021

\section{References}

1. Bray F, Ferlay J, Soerjomataram I, Siegel RL, Torre LA, Jemal A. Global cancer statistics 2018: GLOBOCAN estimates of incidence and mortality worldwide for 36 cancers in 185 countries. CA Cancer J Clin. 2018;68(6):394-424.

2. Kano M, Hayano K, Hayashi H, Hanari N, Gunji H, Toyozumi T, Murakami K, Uesato M, Ota S, Matsubara $H$. Survival benefit of Neoadjuvant chemotherapy with S-1 plus Docetaxel for locally advanced gastric Cancer: a propensity score-matched analysis. Ann Surg Oncol. 2019;26(6):1805-13.

3. Coimbra FJF, de Jesus VHF, Ribeiro HSC, Diniz AL, de Godoy AL, de Farias IC, Felismino T, Mello CAL, Almeida MF, Begnami M, et al. Impact of ypT, ypN, and adjuvant therapy on survival in gastric Cancer patients treated with perioperative chemotherapy and radical surgery. Ann Surg Oncol. 2019;26(11):3618-26.

4. Deng Y, Zhao Y, Fan W, Peng J, Luo X, Mo Y, Xiao B, Zhang L, Pan Z. Preoperative AFU is a useful serological prognostic predictor for colorectal liver Oligometastasis patients undergoing hepatic resection. J Cancer. 2019;10(21):5049-56.

5. Reim D, Choi YS, Yoon HM, Park B, Eom BW, Kook MC, Ryu KW, Choi IJ, Joo J, Kim YW. Alpha-fetoprotein is a significant prognostic factor for gastric cancer: results from a propensity score matching analysis after curative resection. Eur J Surg Oncol. 2017;43(8):1542-9. 
6. Xiao J, Ye ZS, Wei SH, Zeng Y, Lin ZM, Wang Y, Teng WH, Chen LC. Prognostic significance of pretreatment serum carcinoembryonic antigen levels in gastric cancer with pathological lymph node-negative: a large sample single-center retrospective study. World J Gastroenterol. 2017;23(48): 8562-9.

7. Tokunaga R, Imamura $Y$, Nakamura K, Uchihara T, Ishimoto T, Nakagawa S, Iwatsuki M, Baba Y, Sakamoto Y, Miyamoto Y, et al. Carbohydrate antigen 19-9 is a useful prognostic marker in esophagogastric junction adenocarcinoma. Cancer Med. 2015;4(11):1659-66.

8. Emoto S, Ishigami H, Yamashita H, Yamaguchi H, Kaisaki S, Kitayama J. Clinical significance of CA125 and CA72-4 in gastric cancer with peritoneal dissemination. Gastric Cancer. 2012;15(2):154-61.

9. Shimada H, Noie T, Ohashi M, Oba K, Takahashi Y. Clinical significance of serum tumor markers for gastric cancer: a systematic review of literature by the task force of the Japanese gastric Cancer association. Gastric Cancer. 2014;17(1):26-33.

10. Matsuoka T, Yashiro M. Biomarkers of gastric cancer: current topics and future perspective. World J Gastroenterol. 2018;24(26):2818-32.

11. Zou L, Qian J. Decline of serum CA724 as a probable predictive factor for tumor response during chemotherapy of advanced gastric carcinoma. Chin J Cancer Res. 2014;26(4):404-9.

12. Sun Z, Zhang N. Clinical evaluation of CEA, CA19-9, CA72-4 and CA125 in gastric cancer patients with neoadjuvant chemotherapy. World I Surg Oncol. 2014;12:397.

13. Kim DH, Yun HY, Ryu DH, Han HS, Han JH, Yoon SM, Youn SJ. Preoperative CA 125 is significant indicator of curative resection in gastric cancer patients. World J Gastroenterol. 2015;21(4):1216-21.

14. Huang Z, Zhai XM, Wang H, Deng QT, Li K, Liu BS, Wang G, Liu TC. Simultaneous quantitation of carbohydrate antigen 125 and carcinoembryonic antigen in human serum via time-resolved fluoroimmunoassay. Clin Chim Acta. 2018;483:222-6.

15. Namikawa T, Kawanishi Y, Fujisawa K, Munekage E, Iwabu J, Munekage M, Maeda H, Kitagawa H, Kobayashi M, Hanazaki K. Serum carbohydrate antigen 125 is a significant prognostic marker in patients with unresectable advanced or recurrent gastric cancer. Surg Today. 2018;48(4):388-94.

16. Feng F, Tian Y, Xu G, Liu Z, Liu S, Zheng G, Guo M, Lian X, Fan D, Zhang H. Diagnostic and prognostic value of CEA, CA19-9, AFP and CA125 for early gastric cancer. BMC Cancer. 2017:17(1):737.

17. Wada N, Kurokawa Y, Miyazaki Y, Makino T, Takahashi T, Yamasaki M, Nakajima K, Takiguchi S, Mori M, Doki Y. The characteristics of the serum carcinoembryonic antigen and carbohydrate antigen 19-9 levels in gastric cancer cases. Surg Today. 2017;47(2):227-32.

18. Suenaga $Y$, Kanda M, Ito S, Mochizuki Y, Teramoto H, Ishigure K, Murai T, Asada T, Ishiyama A, Matsushita $\mathrm{H}$, et al. Prognostic significance of perioperative tumor marker levels in stage II/III gastric cancer. World J Gastrointest Oncol. 2019;11(1):17-27.

19. Ning S, Wei W, Li J, Hou B, Zhong J, Xie Y, Liu H, Mo X, Chen J, Zhang L. Clinica significance and diagnostic capacity of serum TK1, CEA, CA 19-9 and CA 72-4 levels in gastric and colorectal cancer patients. J Cancer. 2018;9(3):494-501.

20. Jiang Y, Li T, Liang X, Hu Y, Huang L, Liao Z, Zhao L, Han Z, Zhu S, Wang M, et al. Association of Adjuvant Chemotherapy with Survival in patients with stage II or III gastric Cancer. JAMA Surg. 2017;152(7):e171087.

21. Hu PJ, Chen MY, Wu MS, Lin YC, Shih PH, Lai CH, Lin HJ. Clinical Evaluation of CA72-4 for Screening Gastric Cancer in A Healthy Population: A Multicenter Retrospective Study. Cancers (Basel). 2019;11(5):733.

22. Jing J, Ge M, Yang Z, Li P. Spatial distribution characteristics of tumor marker CA724 reference values in China. Cancer Med. 2019;8(9):4465-74.

23. Yang AP, Liu J, Lei HY, Zhang QW, Zhao L, Yang GH. CA72-4 combined with CEA, CA125 and CAl9-9 improves the sensitivity for the early diagnosis of gastric cancer. Clin Chim Acta. 2014;437:183-6.

24. Park JW, Lim SB, Kim DY, Jung KH, Hong YS, Chang HJ, Choi HS, Jeong SY. Carcinoembryonic antigen as a predictor of pathologic response and a prognostic factor in locally advanced rectal cancer patients treated with preoperative chemoradiotherapy and surgery. Int J Radiat Oncol Biol Phys. 2009;74(3):810-7.

\section{Publisher's Note}

Springer Nature remains neutral with regard to jurisdictional claims in published maps and institutional affiliations.

\section{Ready to submit your research? Choose BMC and benefit from:}

- fast, convenient online submission

- thorough peer review by experienced researchers in your field

- rapid publication on acceptance

- support for research data, including large and complex data types

- gold Open Access which fosters wider collaboration and increased citations

- maximum visibility for your research: over $100 \mathrm{M}$ website views per year

At BMC, research is always in progress.

Learn more biomedcentral.com/submissions 